\title{
PROPOSTA DE MELHORIA NOS PROCESSOS DE GESTÃO EM UMA INSTITUIÇÃO DE EDUCAÇÃO BÁSICA: UMA ABORDAGEM A PARTIR DAS FERRAMENTAS DA QUALIDADE
}

\author{
Douglas Freitas Caitano (Universidade do Grande Rio - UNIGRANRIO) df.caitano@gmail.com \\ Sara Evelyn de Souza Soares (Universidade do Grande Rio - UNIGRANRIO) saraevelynsoares@ gmail.com \\ Prof. Dr. Marcos dos Santos, Professor Orientador (Instituto Militar de Engenharia - IME) \\ marcosdossantos_doutorado_uff@yahoo.com.br
}

\begin{abstract}
Resumo
O presente trabalho aborda como as ferramentas da qualidade apoiadas pelos princípios de gestão encontrados na norma ABNT NBR ISO 9001:2015 podem contribuir para a melhoria dos processos em uma Instituição privada de educação básica situada no município de Duque de Caxias, Rio de Janeiro. Além da fundamentação teórica, foi feito um acompanhamento utilizando o MASP com o intuito de detectar quais são os maiores problemas da escola hoje e destes quais poderiam ser solucionados através da utilização de ferramentas e métodos da qualidade. Para tanto, foram enviados aos clientes questionários de satisfação, além da realização de entrevistas com os colaboradores e reuniões junto aos representantes da Instituição. Através dos resultados encontrados foram utilizadas as ferramentas e métodos da qualidade considerados adequados como a primeira etapa do processo de implementação de um SGQ. Este trabalho contribuiu com a elaboração de um organograma, uma política da qualidade incluindo missão, visão e valores, e sugeriu, pautado na ABNT NBR ISO 9001:2015, melhorias para os principais problemas encontrados no IFE e fomenta o início do processo de implementação de um Sistema de Gestão da Qualidade (SGQ). Considerando os resultados obtidos concluiu-se que as ferramentas da qualidade e técnicas de gestão aliadas aos fundamentos da norma ISO 9001:2015 podem contribuir positivamente para a melhoria dos processos de gestão de uma escola.
\end{abstract}

Palavras-Chave: Ferramentas da Qualidade, MASP, ISO 9001, Instituição de Ensino

\section{Introdução}

Um sistema educacional bem estruturado e de qualidade é fundamental para a evolução socioeconômica de um país, uma vez que, existe uma relação direta entre o nível de escolaridade e o aumento da produtividade e renda de uma nação. Esse aspecto torna-se ainda mais relevante para países em desenvolvimento como os da América Latina, por exemplo.

De acordo com pesquisa feita em 2019 pelo Programa Internacional de Avaliação de Estudantes (Pisa), o Brasil ocupa o $57^{\circ}$ lugar em educação, entre 77 países avaliados. Cerca de 731 mil crianças brasileiras ainda estão fora da escola (IBGE). O analfabetismo funcional de pessoas entre 15 e 64 anos foi registrado em $30 \%$ no ano de 2018 (INAF), ou seja, quase um terço da população brasileira é capaz de compreender um texto de média complexidade. $34 \%$ dos alunos que chegam ao $5^{\circ}$ ano de escolarização ainda não conseguem ler. $20 \%$ dos jovens que concluem o ensino fundamental e que moram nas grandes cidades não dominam o uso da leitura e da escrita.

Ao contrário de outros países, no Brasil tanto a qualidade dos professores quanto a qualidade da infraestrutura física e administrativa das escolas interferem no rendimento dos alunos de maneira significativa (ALBERNAZ; FERREIRA \& FRANCO, 2002). A gestão no ambiente escolar brasileiro é então de um elemento crucial da 
eficácia escolar. Portanto, adotar uma postura gerencial eficaz pode contribuir de maneira expressiva para a melhoria do ensino nas escolas brasileiras.

Nos setores produtivos, o uso da norma ISO 9001 como referência para a implementação de um sistema de gestão da qualidade (SGQ) eficaz é bastante difundida, existindo uma quantidade significativa de literatura sobre o assunto. Porém, no setor educacional, sobretudo na educação básica, o assunto é muito pouco desenvolvido.

Já os programas e ferramentas da qualidade são os elementos que permitem operacionalizar efetivamente os preceitos do sistema de gestão da qualidade contidos na norma ABNT NBR ISO 9001:2015 - Sistemas de Gestão da Qualidade - Requisitos. Eles são os instrumentos utilizados para o desenvolvimento, medição, análise e melhoria da qualidade nas organizações. Assim, permitem a identificação e solução dos principais problemas organizacionais e, por este motivo, são importantes instrumentos de diferenciação organizacional (BAMFORD; GREATBANKS, 2005; ALSALEH, 2007).

O Instituto de Formação Ebenézer (IFE) é uma Instituição de Ensino privada em processo de ascensão que tem enfrentado dificuldades envolvendo reclamações constantes de pais relacionadas ao controle de documentos e a padronização de aulas e professores. Como essas reclamações são reincidentes existe uma preocupação por parte da Instituição em evitar a evasão dos alunos.

Neste sentido, este trabalho levanta a questão fundamental a ser respondida: Pode a aplicação de um conjunto de ferramentas da qualidade e técnicas de gestão aliadas às diretrizes contidas na NBR ISO 9001:2015, apoiando-se na norma NBR 15419:2006, obter melhorias para o resultado do negócio em uma Instituição de Ensino Privada?

\section{Referencial Teórico}

\subsection{Gestão Escolar no Brasil}

O grande desafio das Instituições de Ensino consiste em preparar os indivíduos para um mundo cada vez mais globalizado, altamente tecnológico e que oferece um volume enorme de informações complexas (PINTO, 2004). Nesse processo educativo permeado por diversos fatores, como por exemplo, cultura, sociedade e economia, entender sobre a gestão escolar num país significa fazê-lo sob uma perspectiva muito específica, uma espécie de recorte. Ou seja, compreender a gestão escolar no cenário brasileiro é uma tarefa a ser realizada a partir da captação do que foi a redemocratização dessa sociedade, como se dá sua cultura administrativa e organizacional e qual é a função social e política da educação para essa nação (DRABACH E MOUSQUER, 2009).

Portanto, a gestão escolar, abrangendo as gestões financeira, administrativa, de recursos humanos e pedagógica, constitui uma dimensão importantíssima da educação, uma vez que, ela se encarrega de atender as demandas do MEC, é responsável por todas as etapas e atividades que resultam no aprendizado de seus alunos, e possibilita a observação da escola e dos problemas educacionais de forma global (LÜCK, 2009)

\subsection{Gestão da Qualidade}

Segundo Campos (2010), o Sistema de Gestão da Qualidade (SGQ) de uma organização é composto de processos operacionais, processos de suporte e de gestão, sendo mantido através de procedimentos que orientam 
como executar as tarefas e o seu grau de criticidade para a garantia da qualidade, definindo as responsabilidades pela sua execução.

Ainda segundo Campos (2010), uma organização pode optar pela implementação de um SGQ com a finalidade de apenas otimizar seus processos, utilizando os conceitos de um modelo de gestão para melhorar a qualidade de seus produtos e serviços. No entanto, para que esse sistema seja reconhecido formalmente torna-se necessário que seja avaliado e certificado através de uma auditoria por um organismo certificador.

\subsection{Ferramentas da Qualidade e técnicas de gestão}

Conforme Miguel (2006) as ferramentas da Qualidade são usadas normalmente como suporte ao desenvolvimento da qualidade ou ao apoio à decisão na análise de determinado problema, sendo excelentes aliadas na identificação das causas raízes dos problemas e solução dos mesmos. Serão abordadas no referencial teórico as ferramentas e técnicas utilizadas no estudo de caso: MASP, histograma, diagrama de causa e efeito, matriz GUT e $5 \mathrm{~W} 2 \mathrm{H}$.

\subsubsection{Histograma}

Um histograma é uma representação gráfica precisa da distribuição de dados numéricos, uma estimativa da distribuição de probabilidade de uma variável contínua, que foi introduzida pela primeira vez por Karl Pearson. Ele deve ser utilizado quando os dados são numéricos e se deseja visualizar a forma da distribuição dos mesmos. A utilização de um histograma também pode ser útil na análise de um processo, auxiliando a perceber se ele pode ou não atender aos requisitos do cliente. O gráfico também ajuda na avaliação do aspecto da saída do processo de um fornecedor e possibilita visualizar se uma mudança de processo ocorreu de um período de tempo para outro (SOUZA, 2003).

\subsubsection{Diagrama de causa e efeito}

De acordo com Ishikawa os problemas podem ser agrupados em seis categorias de causas: método utilizado para realização da atividade, máquina (defeito ou falta de manutenção), medida (decisões sobre o processo), ambiente corporativo, mão de obra (qualificação) e material (qualidade da matéria-prima utilizada). É exatamente por essa classificação que o diagrama também recebe o título de 6M. Ressaltando que nem sempre todos os M's serão aplicáveis ao problema a ser avaliado, o que não configura uma dificuldade (MIGUEL, 2006).

\subsubsection{Matriz GUT}

A matriz GUT é uma técnica de gestão com a finalidade de ajudar as organizações em decisões complexas. Trata-se de uma técnica bem conhecida de priorização de problemas e tomada de decisão, que apesar de ser muito simples, é realmente eficiente na maioria dos casos.

GUT é uma sigla para Gravidade, Urgência e Tendência. A ferramenta pode ser utilizada para análise de problemas internos ou externos da organização e se diferencia por possibilitar uma avaliação quantitativa do 
problema, o que permite o gestor priorizar as ações corretivas e preventivas a serem tomadas, de modo a eliminar parcial ou totalmente o problema (LEAL et al.,2011).

Figura 1 - Matriz GUT
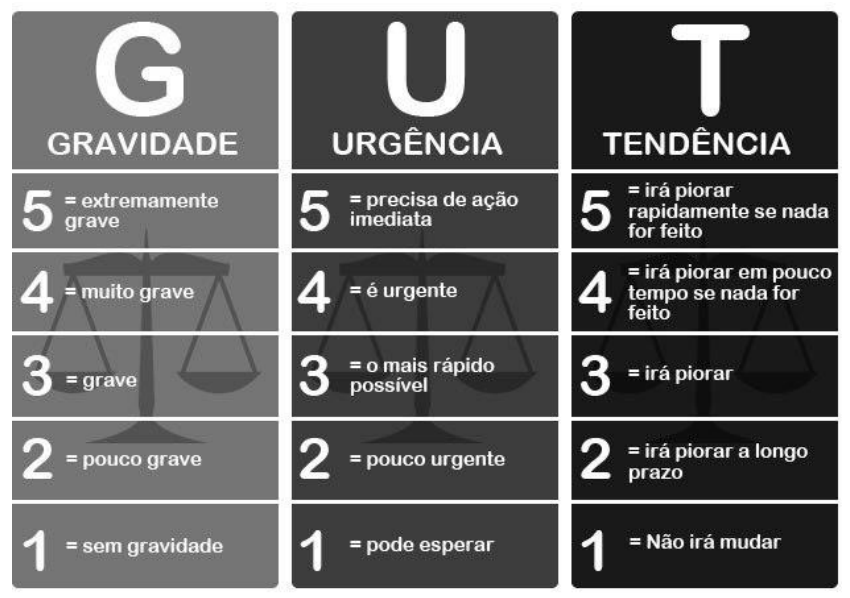

Fonte: Daychoun (2013)

\subsubsection{W2H}

De acordo com Daychoum (2013) o 5W2H pode ser definido como uma ferramenta para o planejamento para as soluções de problemas onde, fornece perguntas orientadoras para a análise de um processo. O nome $5 \mathrm{~W} 2 \mathrm{H}$ vem das letras iniciais (em inglês) das perguntas diretrizes a serem feitas:

5W - Who (Quem); What (O que); When (Quando); Where (Onde) e Why (Por que).

2H - How (Como) e How much (Quanto).

De acordo com Lisboa e Godoy (2012), essas perguntas impelem os gestores a levarem em conta as diversas perspectivas da situação a ser avaliada.

O que se espera como resposta para cada pergunta:

What - Descrição apropriada da atividade ser realizada;

Who - Indivíduos associados a execução dessa atividade;

Where - Local onde a atividade será executada;

When - Prazo para realização da ação;

Why - Explicação para a execução da ação;

How - Como essa ação será executada;

How much - Quanto custará o desenvolvimento dessa atividade 


\subsubsection{MASP}

Segundo Carpinetti (2012), MASP é a sigla para Método de Análise e Solução de Problemas. Esse método é um processo de melhoria, que assim como o diagrama de causa e efeito e a matriz GUT ajuda na análise e priorização dos problemas.

De acordo com Menezes (2013), o MASP é composto por oito etapas e sua estrutura é baseada no PDCA. Cada uma das suas etapas corrobora para a identificação e solução dos problemas, são elas: Identificação do problema; observação; análise; plano de ação; ação; verificação; padronização e conclusão.

a) Identificação do problema: Corresponde a definição correta do problema e o reconhecimento da sua importância. É a mais importante das etapas da resolução de problemas;

b) Observação: Investigação minuciosa do problema a partir das mais variadas perspectivas;

c) Análise: Etapa dedicada a encontrar as causas do problema;

d) Plano de ação: Elaboração de um plano para bloquear as causas fundamentais do problema;

e) Ação: Bloqueio das causas fundamentais do problema;

f) Verificação: Constatação da efetividade do bloqueio e de que o problema não acontecerá novamente;

g) Padronização: Etapa de prevenção contra o reaparecimento do problema;

h) Conclusão: Revisão de todo o processo para utilização em situações futuras.

\section{Metodologia}

Este estudo de caso utilizou o método de pesquisa-ação que tem por objetivo gerar conhecimento e solucionar problemas. Macke (2006) afirma que a pesquisa-ação pode ser definida como uma estratégia de condução de pesquisa qualitativa voltada para a busca de solução coletiva a determinada situação-problema, dentro de um processo de mudança planejada. Essa estratégia contempla simultaneamente, processos de pesquisa e intervenção (ação), os quais emergem da participação efetiva dos atores envolvidos e do pesquisador.

O estudo de caso será desenvolvido da seguinte maneira: Primeiro será feita uma Revisão Bibliográfica da literatura disponível, incluindo artigos e livros relevantes no meio acadêmico sobre o tema, sobre o processo de implantação do Sistema de Gestão da Qualidade no setor educacional e a sua importância para a melhoria dos processos educacionais.

A Revisão Bibliográfica será seguida da elaboração de um questionário e observação sistemática que, de acordo com Gil (2007) se caracterizam como técnicas padronizadas para descrever um fenômeno social e comportamental a qual se observa.

Devido ao curto espaço de tempo disponível, este estudo irá focar na identificação dos principais problemas e propor soluções baseadas na ISO 9001:2015 e por consequência, incentivar a Alta direção em progredir com a implantação plena de um SGQ para a melhoria de seus processos. 


\section{Aplicação das ferramentas da qualidade como proposta de melhoria dos processos organizacionais do}

IFE

\subsection{Cenário atual}

Apesar de associar essa recente perda de clientes tendo influência da crise que assola o país, o IFE vem enfrentado graves inconvenientes relacionados a desorganização, como a falta de controle de documentos, a falta de registros e de padronização que têm criado situações adversas no cotidiano da empresa, ela passou a considerar a hipótese de esse ser um viés do motivo para suas perdas financeiras.

Talvez a maior problemática dentre todas as queixas apresentadas pelos clientes seja o fato delas não receberem um tratamento adequado. Não existe um registro dessas reclamações e algumas vezes elas não são levadas adiante pelo funcionário encarregado pelo atendimento, no momento em que o responsável demonstrou sua insatisfação, o que significa que essas reclamações nem sempre são sanadas. A escola precisa então, urgentemente, criar meios de tratar devidamente esses problemas e evidenciar suas soluções, de forma a satisfazer seus clientes.

\subsection{Estruturação da metodologia}

Para estruturar a metodologia da aplicada na resolução dos problemas no IFE, a equipe de implementação dividiu esta metodologia em etapas, listadas no fluxograma (gráfico1).

Gráfico 1 - Fluxograma das etapas desenvolvidas no IFE

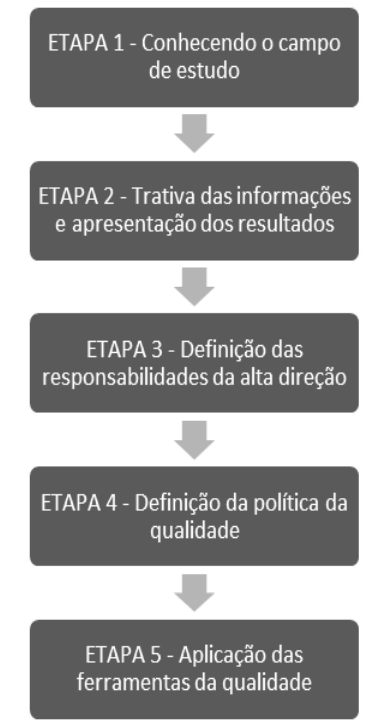

Fonte: Autores (2020)

Etapa 1 - Conhecendo o campo de estudo: Nesta etapa, o objetivo foi levantar informações para poder traçar o perfil da situação atual do IFE, através do levantamento de dados e informações junto aos interessados na 
implantação do SGQ, ou seja, junto à alta direção, aos funcionários, aos membros da equipe de implantação, aos clientes, além de ter analisado toda a documentação gerencial da escola, com o objetivo de detectar problemas prioritários e práticos relacionados à gestão escolar.

O questionário contemplou questões referentes à qualidade do atendimento, da metodologia de ensino, da formação dos profissionais, da infraestrutura da escola e do financeiro. As respostas foram limitadas aos conceitos RUIM, REGULAR e BOM.

Além dos dados levantados através dos questionários aos pais e responsáveis, foram realizadas também entrevistas individuais com os professores e demais funcionários sobre a percepção deles quanto à qualidade do ensino oferecido.

Etapa 2 - Tratativa das informações e apresentação dos resultados: Para a execução desta etapa foram envolvidos:

1) a alta direção: Diretoras da instituição, Coordenadora Pedagógica;

2) o corpo funcional da escola: Professores, Auxiliares dos professores, Secretaria e equipe administrativa;

3) a equipe de implementação: autores do artigo.

A apresentação dos dados coletados por meio dos questionários e entrevistas junto com a leitura dos documentos chave da organização, forneceram uma visão significante do cenário atual da escola. Os dados foram analisados e classificados quanto à sua natureza (Atendimento a reclamações, Padronização de Aulas, Controle de documentos, Financeiro, Mobília, Motivação da equipe, Treinamento, Informatização e Cursos extracurriculares - CEC).

Como o objetivo deste estudo de caso é avaliar quais são os maiores problemas encontrado na gestão do IFE, foram considerados apenas as respostas de grau de intensidade RUIM e REGULAR. Esses dados foram nivelados de acordo com a sua frequência e organizados em um histograma (gráfico 2).

Gráfico 2- Histograma dos problemas de gestão do IFE

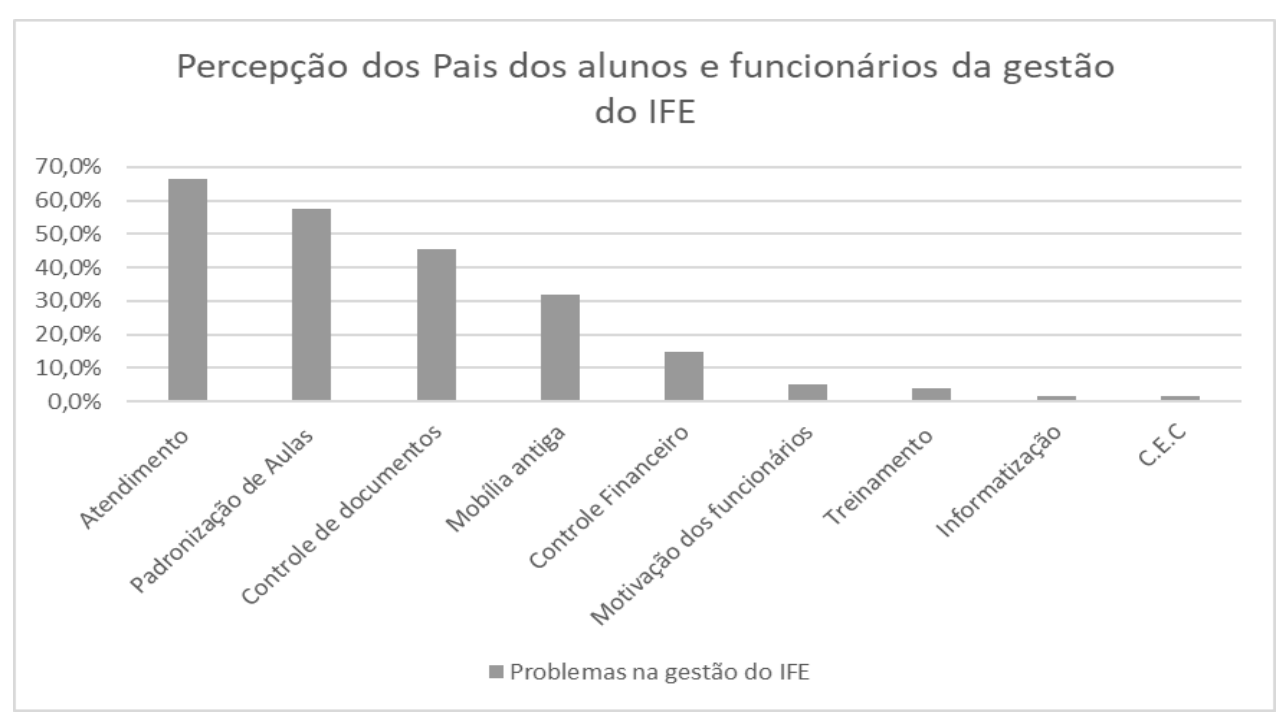

Fonte: Autores (2020) 
Etapa 3: Definição das responsabilidades da Alta Direção: Em reunião, a equipe de implantação pode definir as responsabilidades principais da alta direção.

O objetivo desta etapa foi elucidar a Alta direção A organização deve determinar e prover recursos para implementar e manter o sistema de gestão da qualidade e melhorar sua eficácia e aumentar a satisfação dos clientes mediante o atendimento aos seus requisitos. As pessoas que executam as atividades devem ser competentes, com base em educação, treinamento, habilidade e experiência apropriada.

Nesta etapa também foi elaborado um organograma (gráfico 3) para melhor visualização e entendimento da hierarquia da Instituição.

Gráfico 3 - Organograma do IFE

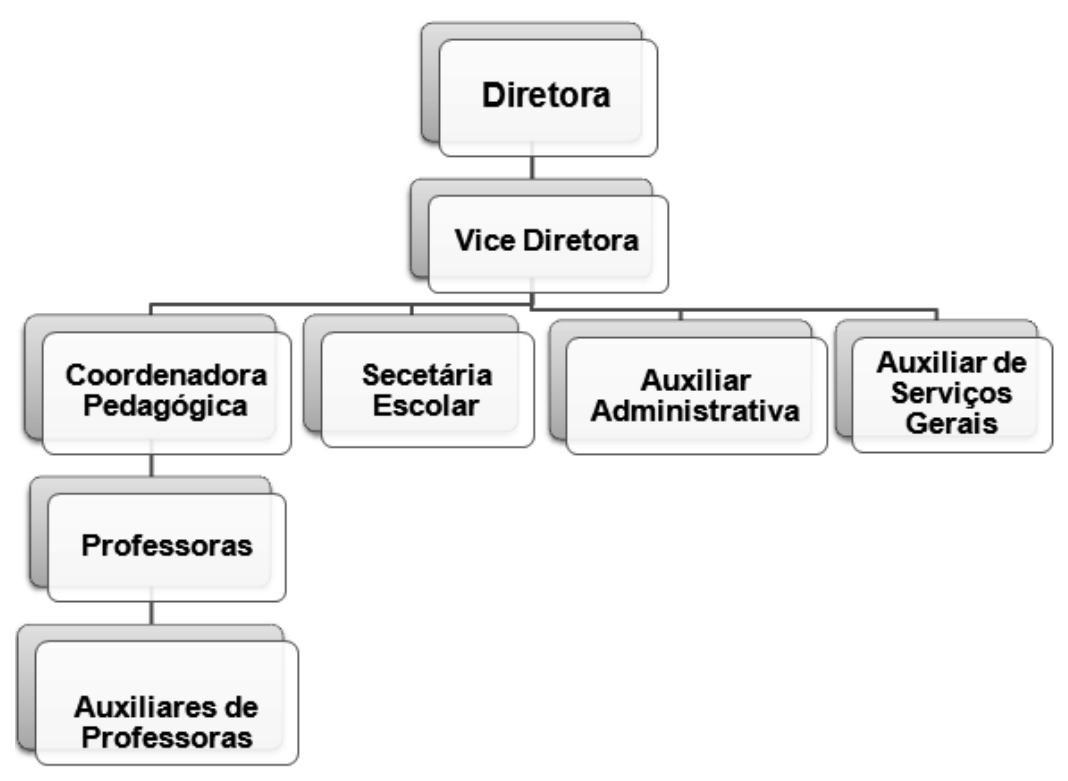

Fonte: Autores (2020)

Etapa 4 - Elaboração da política da qualidade: A equipe de implementação apoiou a instituição no desenvolvimento de sua política, renovando suas estratégias de gestão.

A política da qualidade do IFE foi descrita como: "O Instituto de Formação Ebenézer possui como objetivo principal a plena satisfação dos pais e dos alunos, correspondendo às suas expectativas quanto à qualidade de ensino e à qualidade da infraestrutura da escola. Assim como, através de seus programas escolares, desenvolver nos alunos as vertentes cultural, social, humana, desportiva e tecnológica e incentivar o respeito pelo outro e por si próprio, contribuindo, assim, para o seu enriquecimento pessoal”.

Também foi elaborado o organograma do IFE, para contribuir no claro entendimento da hierarquia da escola e estimular ainda mais a participação da liderança. 
Etapa 5 - Aplicação das ferramentas da qualidade: Nesta etapa foram levantados os principais problemas encontrados nos processos de gestão, seus impactos na qualidade do ensino e na expectativa que os clientes, em como a escolha das ferramentas da qualidade que melhor se apliquem para a solução destes problemas.

Foi elaborado um diagrama de causa-efeito (gráfico 4) para análise das possíveis causas responsáveis pela evasão escolar.

Gráfico 4 - Diagrama Causa-Efeito para a Evasão Escolar

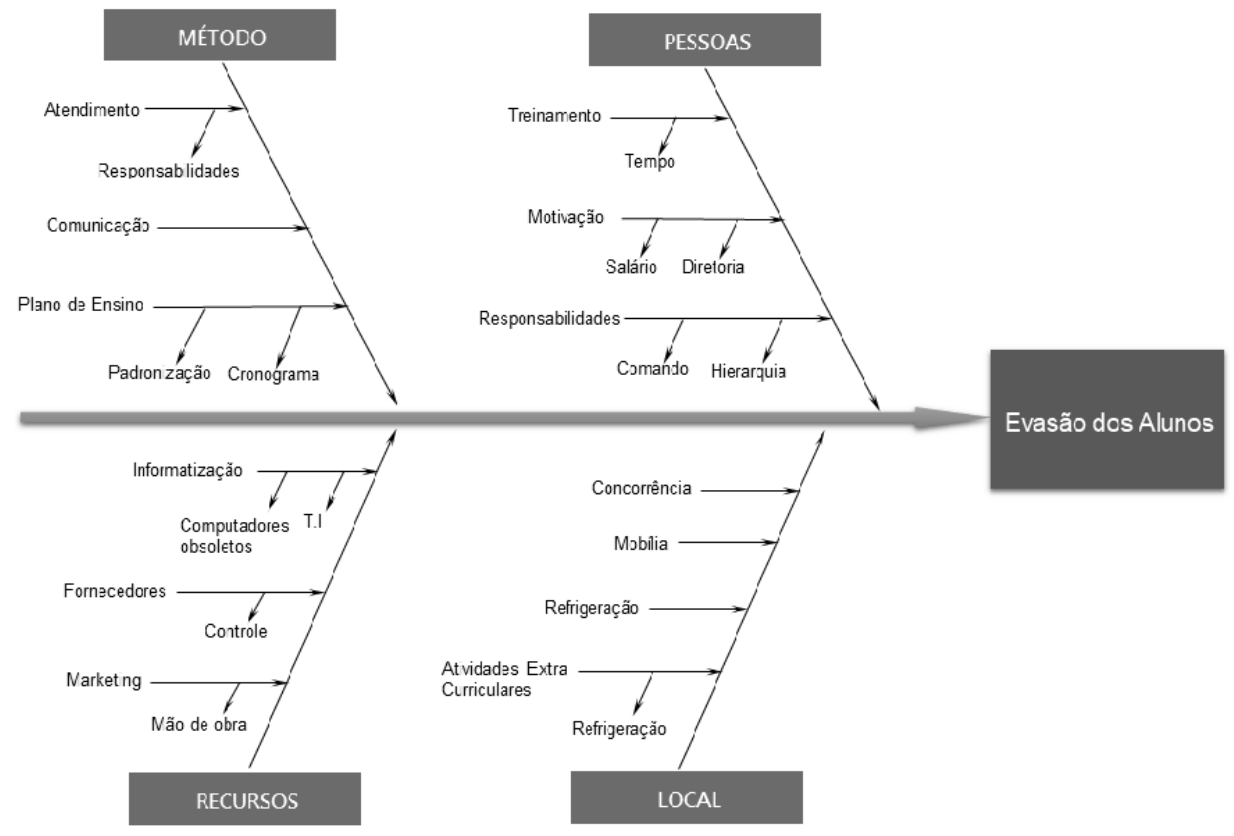

Fonte: Autores (2020)

Depois de identificados e classificados os problemas, é preciso definir a prioridade na solução dos mesmos, a ferramenta escolhida foi a matriz GUT.

Foi preciso determinar como parametrizar cada valor na matriz GUT, ou seja, o que realmente deve ser priorizado no campo de estudo. Para o IFE, a matriz GUT (quadro 1) foi elaborada de acordo com três perguntas principais:

a) Qual a gravidade do problema? Ou seja, qual o impacto do problema, a longo prazo, sobre os clientes, os colaboradores do IFE e na qualidade do ensino?

b) Qual a urgência de se eliminar o problema? Ou seja, quais consequências à curtos prazos podem surgir ou estão surgindo com esse problema?

c) Qual a tendência de crescimento do problema? 
Quadro 1 - Matriz GUT dos problemas de gestão do IFE

\begin{tabular}{|c|c|c|c|c|}
\hline Problema & Gravidade & Urgência & Tendência & Total \\
\hline Reclamações não atendidas & 5 & 5 & 3 & 75 \\
\hline Padronização das aulas & 5 & 3 & 4 & 60 \\
\hline Controle de Documentos & 5 & 3 & 4 & 60 \\
\hline Definição de responsabilidades & 4 & 3 & 4 & 48 \\
\hline Mobília Antiga & 4 & 3 & 3 & 36 \\
\hline Controle Financeiro & 4 & 3 & 3 & 36 \\
\hline Motivação dos funcionários & 3 & 3 & 3 & 27 \\
\hline Treinamento & 3 & 3 & 3 & 27 \\
\hline Informatização & 3 & 2 & 2 & 12 \\
\hline Cursos extracurriculares & 2 & 2 & 2 & 8 \\
\hline
\end{tabular}

Fonte: Autores (2020)

Como observado, os problemas de maior impacto na qualidade da gestão do IFE e consequentemente, na evasão dos alunos são: Tratamento das reclamações, Padronização de Aulas e Controle de Documentos.

Por último, um plano de ação foi desenvolvido para a solução destes problemas. A ferramenta escolhida foi o $5 \mathrm{~W} 2 \mathrm{H}$.

O campo "o quê? (what?)" Foi respondido de acordo com os requisitos da norma ISO 9001:2015 apoiada na ABNT NBR 15419:2006 e baseado em práticas de gestão difundidas na literatura.

O campo "por quê? (why?)" Está diretamente relacionado aos problemas encontrados.

Os campos "onde? (where?), quem? (who?) e quando? (when?)" Foram respondidos juntamente com o consentimento da alta direção.

Os resultados foram apresentados para a alta direção, sendo elaboradas propostas de soluções para os problemas encontrados (quadro 2). 
Quadro 2 - Plano de ação 5W2H

\begin{tabular}{|c|c|c|c|c|c|c|}
\hline \multicolumn{5}{|c|}{$5 \mathrm{~W}$} & \multicolumn{2}{|c|}{$2 \mathrm{H}$} \\
\hline O quê? (What?) & Porque? (Why?) & $\begin{array}{c}\text { Onde? } \\
\text { (Where?) }\end{array}$ & Quem (Who?) & $\begin{array}{l}\text { Quando } \\
\text { (When?) }\end{array}$ & Como? (How?) & $\begin{array}{l}\text { Quanto custa? } \\
\text { (How much?) }\end{array}$ \\
\hline $\begin{array}{l}\text { Criação de um } \\
\text { procedimento } \\
\text { para tratamento } \\
\text { de reclamações }\end{array}$ & $\begin{array}{c}\text { Orientar os } \\
\text { funcionários a } \\
\text { tratarem as } \\
\text { reclamações de } \\
\text { maneira adequada }\end{array}$ & Secretaria & $\begin{array}{c}\text { Secretária e Aux. } \\
\text { administrativa }\end{array}$ & Jan/18 & $\begin{array}{c}\text { Seguindo os } \\
\text { requisitos da } \\
\text { ISO 9001:2015 } \\
\text { - item 8.2.1 e } \\
\text { literatura } \\
\text { pertinente }\end{array}$ & Não se aplica \\
\hline $\begin{array}{c}\text { Criação de uma } \\
\text { caixa de } \\
\text { sugestões }\end{array}$ & $\begin{array}{l}\text { Mecanismo para } \\
\text { facilitar o } \\
\text { entendimento das } \\
\text { expectativas dos } \\
\text { clientes e } \\
\text { colaboradores }\end{array}$ & Secretaria & $\begin{array}{c}\text { Equipe de } \\
\text { Implementação e } \\
\text { auxiliar } \\
\text { administrativa }\end{array}$ & Jan/18 & $\begin{array}{l}\text { Uma caixa do } \\
\text { tipo urna será } \\
\text { fixada ao lado } \\
\text { da secretaria }\end{array}$ & $\mathrm{R} \$ 40,00$ \\
\hline $\begin{array}{l}\text { Criação de um } \\
\text { procedimento } \\
\text { para controle de } \\
\text { documentos }\end{array}$ & $\begin{array}{c}\text { Facilitar a gestão } \\
\text { da informação } \\
\text { documentada }\end{array}$ & Secretaria & $\begin{array}{c}\text { Equipe de } \\
\text { Implementação, } \\
\text { secretária e auxiliar } \\
\text { administrativa }\end{array}$ & Jun/18 & $\begin{array}{c}\text { Seguindo os } \\
\text { requisitos da } \\
\text { ISO 9001:2015 } \\
\text { - item 7.5.3 e } \\
\text { literatura } \\
\text { pertinente }\end{array}$ & Não se aplica \\
\hline $\begin{array}{l}\text { Informatizar a } \\
\text { informação } \\
\text { documentada }\end{array}$ & $\begin{array}{l}\text { Segurança da } \\
\text { informação e } \\
\text { recuperação } \\
\text { dados }\end{array}$ & Secretaria & $\begin{array}{c}\text { Equipe de } \\
\text { Implementação, } \\
\text { secretária e auxiliar } \\
\text { administrativa }\end{array}$ & Jun/18 & $\begin{array}{c}\text { Seguindo os } \\
\text { requisitos da } \\
\text { ISO 9001:2015 } \\
\text { - item 7.5.3 e } \\
\text { literatura } \\
\text { pertinente }\end{array}$ & Não se aplica \\
\hline $\begin{array}{l}\text { Criação de um } \\
\text { procedimento } \\
\text { para } \\
\text { padronização de } \\
\text { aulas }\end{array}$ & $\begin{array}{l}\text { Estabelecer o } \\
\text { mesmo nível de } \\
\text { qualidade das } \\
\text { aulas }\end{array}$ & $\begin{array}{l}\text { Sala de } \\
\text { aula }\end{array}$ & Corpo docente & Jun/18 & $\begin{array}{c}\text { Seguindo os } \\
\text { requisitos da } \\
\text { ISO 9001:2015 } \\
\text { - item } 8.2 \mathrm{e} \\
\text { literatura } \\
\text { pertinente }\end{array}$ & Não se aplica \\
\hline
\end{tabular}

Fonte: Autores (2020)

\section{Conclusão}

As escolas particulares vêm enfrentando mudanças significativas nos últimos anos, novas tecnologias e novos sistemas educacionais acirraram ainda mais a competição entre elas, levando a uma busca por novas ferramentas 
de ensino e formas de atenderem as necessidades dos seus clientes. Logo, a adoção de um sistema de gestão da qualidade eficaz nos processos educacionais busca assegurar que o planejamento, organização, controle e liderança de uma Instituição de ensino sejam conduzidos garantindo a melhoria contínua do seu desempenho.

É de extrema importância que exista uma combinação de processos de gestão de forma a operacionalizá-la dentro do contexto educacional, proporcionando controle e melhoria da qualidade de ensino para obtenção de resultados que se reflitam na melhoria do processo de aprendizagem. Contudo, considerando as informações coletadas na revisão bibliográfica desse trabalho, foi possível perceber que o assunto ainda é pouco abordado, sobretudo na educação básica.

Diante das observações realizadas, o processo de identificação e solução de problemas dentro do ambiente educacional é um caminho para prestação de um serviço com qualidade posicionando a escola estrategicamente frente à concorrência, uma vez que, nesse setor a tangibilidade do conceito qualidade é complexo de se determinar.

Baseado nisso, o presente trabalho analisou de que forma as ferramentas da qualidade apoiadas pelos princípios de gestão encontrados na norma ABNT NBR ISO 9001:2015 poderiam contribuir para a melhoria dos processos em uma Instituição privada de educação básica, gerando valor competitivo. Através do diagnóstico da situação atual da escola em estudo, diagnóstico esse feito através da aplicação, ainda que não completa, do MASP, foi possível detectar problemas substanciais que a Instituição vem enfrentando e então priorizá-los por meio das ferramentas e técnicas da qualidade, e por fim propor soluções eficazes utilizando as diretrizes da NBR ISO 9001:2015. Diante das observações realizadas e do estudo aplicado foi possível perceber que a utilização de ferramentas e métodos da qualidade com vistas a implantação do SGQ dentro do ambiente educacional é um caminho para prestação de um serviço com qualidade, diferenciado e bem posicionado no mercado.

\section{REFERÊNCIAS}

CARPINETTI 2012 CARPINETTI, L. C. R. Gestão da qualidade: conceitos e técnicas. São Paulo. Editora Altas, 2012.

ASSOCIAÇÃO BRASILEIRA DE NORMAS TÉCNICAS. ABNT NBR ISO 9001:2015 - Sistema de Gestão da Qualidade: Requisitos. Rio de Janeiro, 2015

ASSOCIAÇÃO BRASILEIRA DE NORMAS TÉCNICAS. ABNT NBR 15419 Sistemas de gestão da qualidade: diretrizes para aplicação da ABNT NBR ISO 9001:2000 nas organizações educacionais. Rio de Janeiro, 2006

ALBERNAZ, Ângela; FERREIRA, Francisco and FRANCO, Creso. Qualidade e equidade no ensino fundamental brasileiro. PUC/RJ, Rio de Janeiro, v. 32, n. 3, 2002.

BAMFORD, David; GREATBANKS, Richard. The use of quality management tools and techniques: a study of application in everyday situations. International Journal of Quality \& Reliability Management, v. 22, n.4. Emerald Group, 2005

FAGUNDES, Carlos. O desempenho acadêmico como indicador de qualidade da transição Ensino MédioEducação Superior. Revista Ensaio: Avaliação e Políticas Públicas em Educação, v. 22, n. 84, p. 635-670, 2014. 
CAMPOS, Vicente Falconi. Gerenciamento pelas diretrizes. 4.ed. São Paulo: Atlas, 2010.

LÜCK, Heloisa et al. A escola participativa: o trabalho do gestor escolar. Rio de janeiro: DP\&A editora, 2009.

MENEZES, F. M. Metodologia de Análise e Solução de Problemas. ABDI. Porto Alegre, 2013.

MIGUEL, Paulo Augusto. Qualidade: enfoques e ferramentas. 1 ed. São Paulo: Artliber, 2006.

PINTO, Aparecida Marcianinha. As novas tecnologias e a educação. Paraná, 2004.

SOUZA, Robson. O programa Seis Sigma e a melhoria contínua. FGV. São Paulo, 2003.

XAVIER, A.C da R. Rompendo paradigmas: a implantação da gestão da qualidade total nas escolas municipais de Cuiabá. Brasília: IPEA, 1994. 